\title{
SISTEMA DE CAPACIDADES PARA \\ EL DESARROLLO SOSTENIBLE DE MUNICIPIOS INTELIGENTES DE MAYABEQUE (CUBA)
}

\author{
Alejandro Emilio Ramos Rodríguez \\ Universidad Agraria de la Habana \\ San José de las Lajas - Mayabeque - Cuba \\ E-mail: alerr@unah.edu.cu
}

ORCID: https://orcid.org/0000-0001-7498-2420

\section{Elaine Artigas Pérez}

Universidad Agraria de la Habana

San José de las Lajas - Mayabeque - Cuba

E-mail: elaine_artigas@unah.edu.cu

ORCID: https://orcid.org/0000-0002-4905-7265

\author{
Aimara Brito Montero \\ Universidad Agraria de la Habana \\ San José de las Lajas - Mayabeque - Cuba \\ E-mail: aymarabm@unah.edu.cu \\ ORCID: https://orcid.org/0000-0002-0239-0909 \\ Recebido em 13/08/2021. Aprovado em 01/09/2021. \\ DOI: http://dx.doi.org/10.5380/guaju.v7i2.82430
}

\section{Resumen}

La Universidad Agraria de la Habana y el Centro de Estudios para la Gestión del Desarrollo, como parte de su responsabilidad social en su aproximación a la complejidad municipal, se ha de manifestar de manera integrada en la gestión del conocimiento para el desarrollo como responsabilidad social universitaria con la triple hélice social para el desarrollo, asumiendo la teoría del desarrollo humano en la formación de capacidades técnicas y funcionales, que visualiza el desarrollo no de los procesos sino de las personas en la consecución de municipios inteligentes por un desarrollo sostenible. Es objetivo en la investigación, definir un sistema de formación de capacidades tomando en consideración los elementos de referencia que deben influenciar la forma de pensar, decidir y actuar de los gestores en el municipio, en correspondencia con las unidades de análisis que se estudian e investigan, más los procesos para la consecución de municipios inteligentes por un desarrollo sostenible. La metodología utilizada es la investigación acción participativa e instrumentos para la evaluación de capacidades de los actores y la construcción social desde el diálogo de actores.

Palabras-claves: Gestión del conocimiento. Triple hélice social para el desarrollo. Sistema de capacidades. Desarrollo sostenible. Municipio inteligente. 


\title{
System of capacities for the sustainable development of intelligent municipalities de Mayabeque (Cuba)
}

\begin{abstract}
The Agrarian University of the Havana and the Center of Studies for the management of the Development like part of their social responsibility in their approach to the municipal complexity must be manifested in way integrated in the management of the knowledge for the development like responsibility social university student with the triple social helix for the development, assuming the theory of the human development in the formation of technical and functional capacities that not visualizes the development of the processes but of people in the attainment of intelligent municipalities for a sustainable development. It is objective in the investigation, to define a system of formation of capacities taking in consideration the reference elements that they should influence the form of thinking, to decide and to act of the agents in the municipality in correspondence with the analysis units that are studied and they investigate more the processes for the attainment of intelligent municipalities for a sustainable development. The used methodology is the investigation action participativa and instruments for the evaluation of the actors capacities and the social construction from the dialogue of actors.

Keywords: Management of the knowledge. Triple social helix for the development. System of capacities. Sustainable development. Intelligent municipality.
\end{abstract}




\section{Introducción}

Es función social de las instituciones de Educación Superior, de su red de Centros Universitarios Municipales, de los Centros de Investigación, formar capacidades y competencias para el desarrollo sostenible en los municipios, lo que conlleva a pensar y actuar de manera diferente para alcanzar nuevos resultados. Para ello es imprescindible la integración de la triple hélice social para el desarrollo. Cuando se refiere a la triple hélice social, cada hélice representa a la universidad, el gobierno, y la comunidad de los municipios, cada una de ellas con sus funciones específicas en la construcción del desarrollo sostenible. La integración de la triple hélice social para el desarrollo garantiza la construcción colectiva de nuevos conocimientos, actitudes y prácticas, posibilitando profundos cambios en correspondencia con la actualización del modelo de desarrollo, hacia un futuro próspero y sostenible, proceso gestado en entornos grupales, organizacionales y comunitarios abiertos a la interacción social, cuyos actores dicen, hacen y deciden (OJEDA; RAMOS, 2013; RAMOS et al., 2018).

La gestión del conocimiento responsabilidad social de las universidades es relevante en la construcción del desarrollo sostenible, siempre y cuando se tenga en cuenta que la sostenibilidad implica cultivar las condiciones y relaciones que generan y sostienen la vida, lo que sólo puede emerger de la interacción humana, movilizando la imaginación, creatividad, capacidad y compromiso de los actores en los procesos de gestión para el desarrollo sostenible de los municipios; que incluye a sus organizaciones, comunidades, empresas, contextos. En todo caso siempre se debe estudiar multidimensionalmente en, lo económico, lo social, lo cultural, ambiental, lo ecológico, lo ético, lo humano. Además, se incluye investigaciones inter y transdisciplinarias, por la complejidad y diversidad del desarrollo sostenible que exige una comprensión amplia y múltiple sobre la realidad social (DE SOUZA, 2011, 2014; BERTONI et al., 2011; DUBOIS, 2014; BOUSKELA et al., 2016).

Hacia el desarrollo sostenible de municipios inteligentes en su epistemología, propone la comprensión de los procesos a través de los cuales estos actores construyen sus percepciones de la realidad, que si es socialmente construida puede ser socialmente transformada, si se logra transformar la percepción de estos actores sociales. En su metodología, prevalecen los métodos interactivos que incluyen la participación de los actores del contexto bajo investigación. Si se quiere transformar la realidad se tiene que lograr primero la transformación negociada de la percepción de esta realidad. En su 
dimensión axiológica, el constructivismo revela que no existe práctica social, incluyendo la práctica científica, sin la presencia activa de valores e intereses humanos, que deben quedarse explícitos al inicio de cualquier interacción.

Al asumir el desarrollo como un proceso de gestión social, de carácter complejo, multidimensional, intertransdiciplinariamente, cada área del conocimiento, debe asumir no solo formar las capacidades técnicas propias para un ingeniero, licenciado, sino además las capacidades funcionales que debe poseer al graduarse en la que debe tributar a la gestión del desarrollo sostenible, con capacidades que le permitan pensar en un análisis multidimensional e interdisciplinariamente, en la gestión, planificación y proyección para el desarrollo. Sin embargo, este análisis de no solo formar capacidades técnicas, sino además capacidades funcionales para el desarrollo en cada una de las profesiones suplirían las insuficientes capacidades para el desarrollo de los profesionales que se forman y los que ya están formados y lo hacen de forma desactualizada, con modelos mentales no coherente y que correspondan al concepto de desarrollo que se debe tener hoy y en el futuro (DE BERTONI et al., 2011; DUBOIS, 2014; COSTAMAGNA; LARREA, 2017).

Lo anterior permite determinar la situación problemática de partida, en la necesidad de fortalecer el proceso de gestión del conocimiento, mediante un sistema de capacidades para el desarrollo sostenible de municipios inteligentes entre la universidad, los gobiernos y la comunidad, como parte del proceso de formación de capacidades y competencias continúa de los actores locales, en la consecución de contextos inteligentes y de solucionar las insuficiencias que se manifiestan en la realidad municipal durante la realización de dicho proceso, por la contradicción existente entre las capacidades que poseen los actores de la triple hélice social para el desarrollo y las que deben poseer para construir un Municipio Inteligente por un desarrollo Local Sostenible.

Es objetivo en la investigación, definir un sistema de formación de capacidades, tomando en consideración los elementos de referencia que deben influenciar la forma de pensar, decidir y actuar de los gestores en el municipio, en correspondencia con las unidades de análisis que se estudian e investigan más los procesos para la consecución de municipios inteligentes por un desarrollo sostenible.

Resulta oportuno señalar la necesidad de un sistema de capacidades en la construcción del desarrollo sostenible, como un todo integrado de las unidades de análisis en este caso: (i) la responsabilidad social universitaria para el desarrollo sostenible desde la gestión del conocimiento y de sus procesos sustantivos de formación - ciencia e innovación 
- extensión; (ii) integración Universidad - Gobierno - Comunidad como Triple Hélice Social para el Desarrollo; (iii) Municipio Inteligente, o contexto inteligente como base del desarrollo sostenible; (iv) teoría y enfoques del desarrollo sostenible; (v) formación de capacidades para el Desarrollo Sostenible

Estas unidades de análisis en su momento han sido estudiadas por separados y han dado origen a publicaciones sobre cada uno de esos temas en particular. Al concebir el presente artículo con estas unidades de análisis se tomaron elementos esenciales planteados en esas publicaciones y se situaron en este artículo con una visión articulada para la consecución del desarrollo sostenible de municipios inteligentes, a partir de un sistema de capacidades.

En realidad, el presente artículo en su planteamiento exige de un sistema de capacidades para la consecución del desarrollo sostenible con una visión integrada de las unidades de análisis o variables tratadas aquí. El sistema de capacidades para el desarrollo sostenible no es posible tratando las unidades de análisis por separado; es necesario de una visión holística. Es decir, que este artículo es una integración de las diferentes publicaciones relacionadas con las unidades de análisis para la definición de sistema de capacidades para el desarrollo sostenible.

El estudio se inscribe desde el enfoque de la teoría crítica. La metodología utilizada es la investigación acción participativa y como instrumentos, el taller investigativo, la construcción social desde el diálogo de actores desde el análisis de contenido, análisis de textos y análisis de conversación, instrumentos para diagnosticar capacidades de los actores de la Universidad, Gobierno, Comunidad, el taller investigativo que comprende: (i) etapas de encuadre; (ii) diagnóstico; (iii) identificación - valoración y formulación de las líneas de acción requeridas y, por último, (iv) estructuración y concertación del resultado.

La Universidad como parte de su responsabilidad social ,en su aproximación a la complejidad municipal, se ha de manifestar de manera integrada en la gestión del conocimiento para el desarrollo como responsabilidad social universitaria con la triple hélice social para el desarrollo, asumiendo la teoría del desarrollo humano en la formación de capacidades técnicas y funcionales, lo que implicó una amplia y profunda reflexión teórica sobre el desarrollo y la realización de una extensa revisión bibliográfica.

La metodología de la Investigación Acción Participativa se convierte en la presente investigación en una corriente metodológica que busca obtener resultados fiables y útiles para mejorar situaciones colectivas, basando la investigación en la participación de 
los propios colectivos a investigar. Desde esta visión de solucionar o mejorar problemas colectivos, como un proceso en el cual, los actores sociales no son solo considerados como simples objetos pasivos de investigación, transformándose cada vez más, en sujetos que conducen una investigación con la colaboración de investigadores, un hecho que les permite en la presente investigación demostrar la necesidad de un sistema de capacidades a partir de las unidades de estudios analizadas y de los procesos de gestión para el desarrollo, en la construcción del desarrollo sostenible en contextos inteligentes.

El trabajo está estructurado en cinco tópicos. Inicialmente una introducción al tema sobre sistema de capacidades en la construcción del desarrollo sostenible. El segundo tópico relacionado con la revisión de la literatura abarca las unidades de análisis como un todo integrado para el logro del desarrollo sostenible. En el tercero de los tópicos se trata la situación actual de las capacidades de los actores de la triple hélice social para el desarrollo sostenible de municipios estudiados. El cuarto tópico presenta una visión integradora de las unidades de análisis para un sistema de capacidades en la construcción del desarrollo sostenible y el quinto de los tópicos presenta las consideraciones finales.

\section{Responsabilidad social universitaria}

Avanzar hacia modelos de municipios y contextos inteligentes en la construcción de desarrollo sostenible requiere de la activa participación de todos los actores sociales implicados en dichos procesos, en cada uno de los diferentes contextos. En este sentido, las universidades poseen un rol fundamental dirigido hacia la formación de capacidades y competencias, con incidencia directa o indirecta, hacia el resto de los actores sociales implicados en los procesos de desarrollo a nivel contextual, en sus diversas dimensiones. Por ello, actualmente se reconoce que una organización que quiera ser competitiva en el futuro tendrá que contar con una estrategia que actúe en favor del entorno del que forma parte y en el que desarrolla su actividad, comprometiéndose de esta forma con los principios y/o postulados de lo que se conoce como Responsabilidad Social Universitaria (RSU) (UNESCO, 2009; GAETE, 2015; RAMOS; ARTIGAS; BÁEZ, 2015).

Las organizaciones ejercen su responsabilidad social cuando satisfacen las expectativas que sobre su comportamiento tienen los diferentes grupos de interés, contribuyendo a un desarrollo sostenible y viable. Hoy se asegura que la formación y el conocimiento son factores clave en el desarrollo de un país, y de ahí la necesidad de un sistema universitario bien coordinado, competitivo y con criterios de calidad que permitan 
reorientar las actividades de la universidad para asegurar un mayor compromiso social. En definitiva, las universidades, como formadoras de las presentes y futuras generaciones, y como referente en la generación de conocimientos, deben responder a las necesidades y expectativas de los diferentes actores sociales con los que se relacionan

En este mismo orden, Vallaeys (2014) refiere que la RSU es una nueva filosofía de gestión universitaria que pretende renovar el compromiso social de la Universidad, al mismo tiempo que facilita soluciones innovadoras a los retos que enfrenta la educación superior en el contexto de un mundo globalizado pero insostenible en sus patrones de desarrollo. De acuerdo con Gaete (2015), el papel de la Universidad en este sentido se ha de poner de manifiesto a través del ejercicio de sus diferentes funciones en el contexto del que forma parte. Asumir sus funciones, desde la responsabilidad social, supone un compromiso de toda la organización universitaria con la formación ciudadana, democrática y sostenible, y también, con la inclusión social y la riqueza de las redes sociales, en definitiva, con la calidad de vida en sentido general. En efecto, Gaete (2015) afirma que la responsabilidad social universitaria tiene dos estadios de acción claramente diferenciables.

\begin{abstract}
El primero hacia el interior del centro educativo, que debe ser sistemático y desde el primer hasta el último día que el estudiante permanezca en sus instalaciones, básicamente formando valores humanos, solidaridad, tolerancia y principios de convivencia, para crear conciencia sobre su obligación individual y colectiva de ayudar a los más necesitados y mejorar su entorno. Donde deben estar vinculados: directivos, estudiantes, docentes, y administradores. Y, el segundo hacia el exterior de la institución, hacia la sociedad en general, liderando procesos que cumplan finalmente con el objetivo de lograr una sociedad más justa, con acceso al conocimiento, la información y el trabajo, en un marco de respeto por las diferentes culturas y costumbres, el uso adecuado de los recursos y la preservación del medio ambiente (GAETE, 2015, p. 5).
\end{abstract}

Las instituciones de Educación Superior, la Universidad y los Centros Universitarios Municipales (CUM) deben avanzar en la configuración de una relación más activa con sus contextos. La calidad está vinculada a la pertinencia y la responsabilidad con el desarrollo sostenible de la sociedad. Ello exige impulsar un modelo académico caracterizado por: (i) la indagación de los problemas en sus contextos; (ii) la producción y construcción del valor social de los conocimientos; (iii) el trabajo conjunto con los gobiernos y comunidades; (iv) una investigación científica, tecnológica, humanística y artística fundada en la definición explícita de problemas a atender, de solución fundamental para el desarrollo del país, la provincia o los municipios, y el bienestar de la población; (v) una activa labor de divulgación, 
vinculada a la creación de conciencia ciudadana sustentada en el respeto a los derechos humanos y la diversidad cultural; (vi) un trabajo de extensión que enriquezca la formación, colabore en detectar problemas para la agenda de investigación y cree espacios de acción conjunta con distintos actores sociales (UNESCO, 2009; RAMOS, ARTIGAS, BÁEZ, 2015).

\section{Gestión del conocimiento}

Según la Declaración de la UNESCO en la Conferencia Mundial sobre Educación Superior,

[...] las universidades están llamadas a promover, generar y difundir conocimientos por medio de la investigación y, como parte de los procesos universitarios que ha de prestar a la comunidad, proporcionar las competencias técnicas adecuadas para contribuir al desarrollo sostenible desde sus diversas dimensiones, fomentando y desarrollando la investigación científica y tecnológica a la par que la investigación en el campo de las ciencias sociales, las humanidades y las artes creativas (UNESCO, 1998).

Aspecto que se mantuvo en la conferencia realizada en el año 2009, declarando que “Las Instituciones de Educación Superior deben buscar áreas de investigación y enseñanza que puedan apuntar hacia cuestiones relativas al bienestar de la población y al establecimiento de una base local relevante y sólida en ciencia y tecnología" (UNESCO, 2009, p. 12).

El conocimiento universitario está comprometido con el desarrollo en todas sus dimensiones y ello con el propósito de avanzar hacia un modelo de desarrollo sostenible basado en el conocimiento, lo que se ha dado en llamar nuevo desarrollo. El propósito no es solo potenciar la capacidad de conocimiento, sino que la producción de conocimientos por las universidades debe derivar en desarrollo sostenible del municipio y de sus contextos y organizaciones que lo conforman.

El australiano Lueg (2003, p. 20), plantea que "[...] el conocimiento es algo personal y privado que no puede transferirse, y lo que uno cree que es transferible, el conocimiento objetivo, debe siempre ser construido por el oyente; el oyente comprende y el conocimiento objetivo aparece como transferido, pero solamente si él está preparado para comprender". Desde otra óptica Gradillas (2002, p. 33) refiere que, 
[...] es más un proceso de aprendizaje que de gestión; el término gestión de conocimiento ha sido cuestionado, primero porque es un término que procede de las ciencias de los negocios, con la idea de administrar conocimiento como si se tratara de un recurso más en la organización y segundo porque no todo tipo de conocimiento se puede gestionar; el conocimiento tácito es propio e interno a cada persona, es conocimiento personal no codificado y cuando se trata de conocimiento social se trata de una reestructuración intelectual colectiva, imposible de administrar. Se puede gestionar la expresión del conocimiento, pero no el proceso intelectual o el crecimiento del intelecto humano.

La gestión del conocimiento para el desarrollo es uno de los procesos más generales del modelo desarrollo sostenible y dicha gestión se realiza en el contexto de actuación del municipio. El conocimiento es un producto social que reúne en sí muchas cualidades, pero, él solo no puede crear riquezas, es preciso un sistema que lo gestione. El gran reto de la gestión del conocimiento es que el conocimiento propiamente dicho no se puede gestionar como tal. Sólo es posible gestionar el proceso y el espacio para la construcción de conocimiento. Para la gestión del conocimiento la misión fundamental debe ser explotar y formar los activos de conocimiento que posee la organización a fin de que ésta pueda llevar a cabo su misión estratégica.

La Gestión del Conocimiento no es una herramienta infalible, ni absoluta. Solo es válida si se aplica en correspondencia con las condiciones específicas de cada lugar. Pueden existir experiencias parecidas; pero cada una es particular e irrepetible. Bajo estas concepciones, puede provocar la ruptura sutil de la cotidianidad al crear nuevos espacios de participación que enriquecen la vida espiritual de las personas involucradas y al trasladarse hacia los contextos sociales puede ser un elemento estratégico que contribuya a la inclusión social, al fortalecimiento de la conciencia crítica, de la creatividad como hecho social y personal, al diálogo entre saberes sobre la base de la cooperación entre diferentes actores locales implicados y a la participación social (DE SOUZA, 2011).

La universidad como referente del conocimiento para el desarrollo, entre de los aspectos que debe abordar en la gestión del conocimiento, es su generación, visto como un proceso totalmente humano que parte de la interacción social, de ideas, de la discusión, de la reflexión, de la asimilación a las experiencias de vida y de la transformación de las realidades. Pero generación más en el sentido de construcción social del conocimiento y no de creación, ya que los procesos intelectuales que dan lugar a nuevos conocimientos son en realidad procesos de construcción en los cuales el individuo reestructura no sólo los conocimientos previos sino las propias categorías intelectuales con las cuales se 
representa al mundo. Por lo tanto, el conocimiento no se crea (como si surgiera de la nada de manera espontánea) sino que se construye. Por eso se ha insistido que al construir conocimiento el individuo se construye, porque no sólo cambia su conocimiento viejo por conocimiento nuevo, cambian sus categorías intelectuales y con ello cambia él. La construcción del conocimiento implica la autoconstrucción del individuo (DÍAZ-CANEL, 2012; DE SOUZA, 2014; RAMOS, ARTIGAS, BÁEZ, 2015).

En relación a lo anterior se señala, el conocimiento conecta a los actores de contextos inteligentes que disponen de conocimientos, habilidades, actitudes, valores, prácticas y tecnologías con aquellos que tienen necesidades de los mismas para satisfacer necesidades sociales. En opinión de Díaz-Canel (2012), entonces Ministro de Educación Superior, gestionar conocimiento es que se logre que la gente se apropie del conocimiento, pero que lo aplique de manera transformadora, revolucionaria y en función del desarrollo. Es de significar, que la voluntad es fundamental, más no suficiente. Las personas y los colectivos necesitan contar con marcos filosóficos, conceptuales, programáticos y metodológicos que orienten sus acciones de desarrollo. Pero, además se requiere poner en práctica criterios, creatividad e imaginación para gestionar procesos, entre los que se encuentra la gestión de la información y el conocimiento, la gestión del aprendizaje, la gestión de la diversidad y la gestión de la incertidumbre, entre otros aspectos en la consecución del desarrollo sostenible.

La Gestión del Conocimiento revaloriza también el saber extra académico en los procesos de desarrollo, su fundamento es analizado en el modelo triple hélice social como triada para el desarrollo y constituye parte del modelo municipio inteligente, porque los conocimientos no son un recurso de un determinado sector, ellos existen en todos los sectores de la sociedad y esa cualidad, si se ejercita en un determinado contexto o municipio, puede contribuir al diálogo y a la cohesión social. Mantener en los predios de la vida empresarial, con fines específicamente económicos a un instrumento tan versátil y estratégico como la gestión del conocimiento es una postura errónea, porque la dinámica que encierra puede contribuir al florecimiento de todos los demás procesos que se gestan en la sociedad para el desarrollo, desde lo interdisciplinario, multidisciplinario y transdisciplinario. (LUEG, 2003; BERTONI et al., 2011; DUBOIS, 2014; KARLSEN; LARREA, 2014).

El principio filosófico del desarrollo sostenible se refiere a la permanente generación humana de conocimientos, necesidades, aspiraciones y expectativas y al imperativo de innovar formas creativas de atenderlas sin perjudicar a las sociedades, a las comunidades, a las personas, ni al medio ambiente. La gestión del conocimiento, función social de la 
universidad, implica romper la separación sujeto - objeto, la distancia entre teoría y práctica y entre el saber y el actuar, coloca al sujeto como productor de conocimiento en la reflexión de sí mismo y de su realidad, para sobre esta base generar cambios en forma dinámica en el individuo y en su carácter social.

Los elementos tratados en la Responsabilidad Social Universitaria son efectivos en la construcción del Desarrollo Sostenible si se logra las relaciones funcionales de coordinación y subordinación en la integración Universidad - Gobierno - Comunidad, que se analizará en el siguiente acápite.

\section{Integración Universidad - Gobierno - Comunidad: Triple Hélice Social para el Desarrollo Sostenible}

Vallaeys (2014) y Gaete (2015), al considerar la vinculación como una actividad que requiere ser vista de manera holística, plantean como una nueva función de las universidades, el establecimiento de un nuevo contrato social entre la academia y la sociedad. En este caso, al referirse a una vinculación vista holísticamente, está aludiendo a la integración, que requiere un amplio empoderamiento del gobierno, asignándole a la investigación el papel de eje estructurador de la planeación académica, donde las funciones de formación e investigación universitarias encuentran mecanismos y formas de articulación de manera más estrecha y efectiva con el gobierno y comunidad, salvando el carácter asistencial que hasta antes prevalecía.

La integración social es el proceso mediante el cual la universidad interactúa de manera permanente y organizada con el municipio para cumplir su función social, impulsando el desarrollo humano y equitativo del contexto mediante la educación, la difusión, la generación y aplicación de conocimiento y la creación de espacios colectivos de aprendizaje. La vinculación social se refiere al establecimiento de convenios, programas y proyectos de formación de capacidades y competencias con los sectores gubernamental, empresarial y comunitario, para la comprensión y transformación del entorno, así como al fortalecimiento de los mecanismos de vinculación con visión holística (VALLAEYS, 2014; RAMOS; ARTIGAS; BÁEZ, 2015).

Es preciso integrar los espacios universitarios con los sociales, lograr en toda su magnitud la Triple Hélice Social, para generar ambientes de desarrollo humano que, mediante la educación y participación ciudadana, promuevan el compromiso social así como el desarrollo 
integral y el pensamiento crítico y libre en la ciudadanía; de esta manera, coadyuven a la difusión de la cultura, a la convivencia en la diversidad, al crecimiento individual y comunitario, a la equidad y a un mayor equilibrio social de todos los sectores que integran el municipio, siendo partícipes activos en la conformación de una nueva ciudadanía en una comunidad que aprende, genera capacidades y competencias para comprender y transformarse.

En este sentido, el modelo de la Triple Hélice ha transitado por tres diferentes etapas. En la etapa I, el estado abarca la industria y la academia, además regula las relaciones entre las esferas institucionales. En la etapa II, existe una separación de las esferas institucionales y se circunscriben las relaciones entre ellas, y por último la tercera etapa, refleja la generación de una infraestructura de conocimiento en función de la interrelación de las esferas institucionales. Se observa en la etapa III, que en la evolución del modelo aparece un actor que se identifica como un ente híbrido, que se conceptualiza como agencias pequeñas e intermedias, que no se sitúan dentro de la clasificación de gobierno, empresas y universidad, pero que cumplen más de una de las funciones específicas de los agentes de esta triada (LÓPEZ; MEJÍA; SCHMAL, 2006; CHANG, 2010).

La literatura revisada sienta el precedente e interés de quienes se encuentran activos dentro de universidades o centros de investigación, desarrollen una postura cada vez más intensa, proactiva, responsable y comprometida con el desarrollo de la sociedad, al contribuir desde la academia en el diseño de propuestas y estudios que permitan la óptima interacción sistémica de los sectores académicos, empresariales, gubernamentales y comunitarios, de tal forma que se afiance y gestione el conocimiento, la innovación y la generación del mismo a los sectores interesados (PINEDA, MORALES, ORTIZ, 2012; CELAYA; BARAJAS, 2012; CORRALES, 2014).

De los anteriores planteamientos se deduce dos caminos, estrategias, objetivos y resultados en situación opuesta, y lo más importante, con conocimientos diferentes y consecuencias distintas. A los efectos de lo expuesto, si el enfoque deja de ser empresarial y se dirige a los problemas de la sociedad, significa entonces considerar a la sociedad como una hélice y la empresa como parte de ésta.

En la triple hélice empresarial, el pensamiento simplificador desintegra la complejidad; cabe agregar que el pensamiento complejo integra todos los elementos que puedan aportar orden, claridad, distinción, precisión en el conocimiento, pero rechaza las consecuencias mutilantes, reduccionistas, unidimensionales que pueden producir una simplificación abusiva. El efecto de ésta es ocultar todos los vínculos, las interactuaciones, las interferencias que hay en el mundo real (DE SOUZA, 2011, CORRALES, 2014, RAMOS et al., 2018). 
A lo largo de los planteamientos hechos se aprecia diferencias cuando se hace referencia a la triple hélice empresarial y a la triple hélice social para el desarrollo. En esta última, al considerarse como un proceso de construcción social, multidimensional y contextual, es fundamental para el desarrollo que cada hélice (universidad - gobierno comunidad) interprete el todo, que es dinámico y diferente del conjunto de sus partes, que para comprender su dinámica es necesario comprender la trama de las relaciones y significados cambiantes que lo constituyen (holismo) (DESOUZA, 2011;2014;OJEDA; RAMOS, 2013; RAMOS et al., 2018). Por lo que, se asume en términos prácticos, que el conocimiento generado, a través del modo contextual, asume varios atributos: conocimiento contextual, complejo, transdisciplinario, social, ético y democrático.

La triple hélice empresarial como modelo dinamizador de la transferencias de tecnologías hacia las empresas con un carácter economicista, hoy adquiere una potencialidad necesaria, y aun no suficiente de dinamizar la innovación hacia la sociedad, hacia la comunidad, a partir de extender sus muros académicos hacia la cuadra, el barrio, la circunscripción, el consejo popular, el municipio, transformándose en un laboratorio proactivo, donde los actores sociales, se organizan socialmente para la comprensión y transformación de su contexto en un proceso de desarrollo sostenible, cuestión que se satisface por la triple hélice social para el desarrollo, al menos en él debe ser (OJEDA, RAMOS, 2013; RAMOS et al., 2018).

El modelo Municipio Inteligente para el desarrollo sostenible, es sustentado en la teoría del desarrollo humano, centrado en la ampliación de las capacidades de las personas, en sustitución de una visión empresarial, economicista, mercadológica que se centra en la producción de bienes y servicios. Si para la Triple Hélice Empresarial (Universidad - Gobierno - Empresa) la visión de mercado es primordial, para la Triple Hélice Social para el desarrollo (Universidad - Gobierno - Comunidad) el contexto se convierte en la clave para comprender y transformar el entorno que se enriquece con la consideración de un abanico amplio de dimensiones sociales, económicas, políticas, culturales y ambientales que determinan el bienestar de las personas y la consecución del desarrollo sostenible.

Cabe agregar que la triple hélice social para el desarrollo y la integración de la universidad con los diversos sectores del municipio es un proceso de interacciones entre actores, que se ejecutan desde, con y en el gobierno, quien tiene como función la de gestionar, planificar y dirigir el desarrollo en el municipio. La universidad asume sus funciones de atender y liderar la gestión del conocimiento y su generación mediante los 
procesos de investigación, formación y extensión, contribuyendo a la satisfacción de las necesidades sociales demandadas por la comunidad como protagonistas del desarrollo y resueltas desde la comunidad de conjunto con el Centro Universitario Municipal, con la actualización y generación de conocimientos. Por lo anterior, se requiere el establecimiento de marcos institucionales de normatividad, que faciliten el proceso y que resuelvan la contradicción dialéctica entre la dedicación del académico a la labor tradicional y compartir tiempos con acciones de vinculación e integración. Sin embargo, es necesario que se establezcan políticas con las hélices Universidad - Gobierno - Comunidad en los sectores gubernamental, empresarial y social, para así fortalecer los mecanismos de integración y se establezcan nuevos vínculos, factor determinante para la operatividad del modelo (OJEDA; RAMOS, 2013; CASTILLO; LAVIN; PEDRAZA, 2013; RAMOS et al., 2018)'.

Continuando la construcción de la ruta hacia el desarrollo sostenible en el municipio y sus contextos en la que la responsabilidad social de la universidad con la gestión del conocimiento y sus procesos de formación, ciencia e innovación y extensión facilita y viabiliza ese desarrollo, en consonancia con la triple hélice social para el desarrollo - Universidad Gobierno - Comunidad, corresponde a continuación un análisis y articulación con lo que refiere los municipios y contextos inteligentes.

\section{Municipio inteligente}

En el panorama, una de las necesidades ingentes que plantea hoy la vida sociopolítica cubana es la de introducir transformaciones que doten a las municipalidades, dentro de la mecánica pública nacional, de un valor existencial y funcional mucho más intenso y decisivo en la consecución de los intereses locales y nacionales, y en la realización de los fines de la comunidad políticamente organizada, que el estado encarna (MATILLA, 2015). La Constitución de la República de Cuba, en su artículo 168 define:

\footnotetext{
El municipio es la sociedad local, organizada por la ley, que constituye la unidad política-administrativa primaria y fundamental de la organización nacional; goza de autonomía y personalidad jurídica propias a todos los efectos legales, con una extensión territorial determinada por necesarias relaciones de vecindad, económicas y sociales de su población e intereses
}

1 Es de significar que para sintetizar sobre la triple hélice social para el desarrollo se tuvo en cuenta otros enfoques similares sobre el tema, a ejemplo de: González (2009); Leydesdorff $(2010,2013)$; Luengo y Obeso (2013); López 2014; Büttenbender y Sausen (2020). 
de la nación, con el propósito de lograr la satisfacción de las necesidades locales. Cuenta con ingresos propios y de las asignaciones que recibe del Gobierno de la Republica, en función del desarrollo económico y social de su territorio y otros fines del Estado, bajo la dirección de la Asamblea Municipal del Poder Popular (CUBA, 2019, p. 135).

En lo planteado, no debe olvidarse que, para que las transformaciones a promover en los municipios lleguen realmente a ser funcionales, efectivas, no solo deben emprenderse desde el impulso de los intereses políticos que animan el actuar del Estado, sino también $y$, sobre todo, desde la realidad de las cosas que evidencia el desenvolvimiento material e inmaterial de la cotidianidad socio, política, económica, cultural y ambiental. Todo ello debe estar respaldado por una adecuada percepción de los fenómenos objetivos y subjetivos del contexto municipal. Estos planteamientos sobre municipio conllevan a pensar y actuar de manera diferente y transitar de municipios tradicionales en la actualidad a la consecución de Municipios Inteligentes (RAMOS et al., 2017).

El municipio inteligente se concibe como un espacio delimitado, territorial y geográficamente, en donde convergen las iniciativas locales a través del esfuerzo concertado de los diferentes actores que hacen vida en las comunidades, con el fin de llevar adelante la gestión pública de una forma más participativa y democrática. Esta acción se focaliza en el ámbito político territorial del municipio y resulta de la agrupación de actores sociales, los cuales conservan sus particularidades endógenas y características autóctonas, lo que constituye una de las principales características (OJEDA; RAMOS, 2013). La inteligencia municipal es la información y el conocimiento que se posee por los actores del municipio, para su transformación en los diferentes ejes temáticos de desarrollo. El aprendizaje para la innovación es contextual, lo que implica formar constructores de caminos, que aprenden en interacción con el contexto, inventado desde las historias, experiencias y saberes locales, para no perecer imitado desde los diseños globales creados en otros lugares, por otros actores.

Tres son los procesos más generales para la consecución de municipios inteligentes. En primer orden, la base teórica y metodológica para el desarrollo a construir; un segundo proceso se relaciona con la gestión para el desarrollo; y el tercero, con la educación para el desarrollo. Estos propician la relación multidimensional y la visión inter y transdisciplinar del desarrollo sostenible, a partir de la acción social de los actores locales y sus instituciones, en la organización social para la toma de decisiones, contribuyendo con la participación de todos los miembros de un territorio determinado, los cuales hacen vida activa dentro de la misma, con compromiso de gestión social (RAMOS; ARTIGAS; BRITO, 2018). Un Municipio 
Inteligente coloca a las personas en el centro del desarrollo, incorpora las tecnologías de la información y las comunicaciones en la gestión para el desarrollo y usa estos elementos como herramientas para estimular la formación de un gobierno eficiente que incluya procesos de planificación colaborativa y de participación ciudadana. Al promover un desarrollo sostenible, los Municipios Inteligentes se tornan más innovadores, competitivos, atractivos y resilientes, mejorando así calidad de vida.

El proceso de transformación de modelos de gestión tradicional de municipios en modelos inteligentes, es vital para lograr la sostenibilidad de los municipios a mediano y largo plazo. El camino a la modernización y transparencia de los gobiernos exige, fundamentalmente, evolucionar del modelo de gestión tradicional a un modelo de gestión inteligente, combinando teorías, modelos, tecnología, personas y procesos de formas innovadoras. Si los antiguos compartimentos desaparecen y los sistemas de gobierno de misión crítica se relacionan entre sí e intercambian información por medio de canales digitales, permitiendo que los gestores y funcionarios de diferentes sectores trabajen como equipos dentro de una visión integrada, colaborativa y siempre actualizada, se estará construyendo Municipios Inteligentes y contextos inteligentes (MUJICA DE LÓPEZ et al., 2009; OJEDA; RAMOS, 2013; DE SOUZA, 2014, BOUSKELA et al., 2016).

La transformación de un municipio tradicional en un municipio inteligente no es simple y exige el compromiso de los líderes ejecutivos, de los diferentes sectores de la gestión pública y de la triple hélice para el desarrollo. Es fundamental entender ese plan para el desarrollo a partir de una visión integrada, multidimensional, multisectorial, interdisciplinaria, transdisciplinaria y colaborativa. En el Modelo Municipio Inteligente por un Desarrollo Sostenible supone un reto importante, pues se trata no de analizar la innovación social desde fuera, sino de construirla en interacción con los demás actores del territorio, es decir, con el consenso y negociación de cada una las hélices que, integradas, posibilitan la construcción del desarrollo y su sostenibilidad.

Rediseñar municipios para que ellos se vuelvan inteligentes exige la combinación de esfuerzos y conocimientos diversos. Muchos proyectos tropiezan ante la falta de equipos interdisciplinarios y transdisciplinario capaces de ponerlos en práctica. La integración y cohesión están en el corazón de cada Municipio Inteligente. Quebrar los depósitos que suelen dividen los sectores de la administración pública es fundamental para evitar las llamadas"islas" de automatización y de gestión; así, se logra economizar tiempo y dinero en la implementación de los sistemas y la infraestructura de comunicación, y se evita la duplicidad 
y la superposición de esfuerzos. Los equipos deben tener competencias complementarias y trabajar en conjunto. Si fuera necesario, se debe recurrir a alianzas para suplir carencias de capacidades funcionales (OJEDA; RAMOS, 2013; DE SOUZA, 2014; SOLER, 2017).

Precisando de una vez, el Municipio Inteligente por un Desarrollo Sostenible, concepto construido por el Centro de Estudios para la Gestión del Desarrollo, presenta puntos convergentes y divergentes con los enfoques tratados por la bibliografía revisada sobre Territorios o Municipios Innovadores, Ciudades Inteligentes e incluso Municipios Inteligentes, llamados asítambién en otros países. La principal diferencia es queestos enfoques mencionados se centran en los procesos tecnológicos y de mercado en primer orden, mientras para el Centro de Estudios el Municipio Inteligente por un Desarrollo Sostenible el enfoque se centra en la ampliación de las capacidades de las personas y en el contexto de actuación, para comprender y transformar al municipio de lo tradicional a lo inteligente.

Otro de los aspectos que marca diferencia con el enfoque de Municipio Inteligente por un Desarrollo Sostenible del Centro de Estudios es la combinación del pensamiento duro con el pensamiento blando, con el último prevaleciendo sobre el primero. La prevalencia del pensamiento duro de la época del industrialismo ha creado la actual vulnerabilidad, que se mantiene cuando la tecnología y el mercado son el centro en Territorios o Municipios Innovadores, Ciudades y Municipios Inteligentes, disminuyendo la relevancia del lado blando de la realidad municipal, que incluye los procesos, las relaciones, las conexiones, las interacciones, las interdependencias, las contradicciones, las implicaciones, las cadenas de impacto, etc., que caracterizan y aportan significado a la dinámica compleja y cambiante de la vida del municipio.

Un Municipio Inteligente en su construcción se inicia desde las responsabilidades y funciones de cada una de las hélices para el desarrollo, su integración, vinculación e interacción, donde el aprendizaje juega un papel fundamental, más aún lo juega el reaprendizaje, que implica nuevas formas de aprehender y comprender las realidades para, desde allí, transformarlas en función de horizontes de sentido compartidos colectivamente. Los procesos de aprendizaje, desde este enfoque, se fundamentan en las premisas de que el conocimiento se construye colectivamente, requiriendo una generación desde diálogos de saberes. Implica diálogos entre saberes: académicos o científicos y saberes "populares", ancestrales y acumulados por la experiencia, interdisciplinarios, transdisciplinarios articulados desde distintas disciplinas o ciencias, sobre fenómenos que no pueden ser comprendidos desde una sola de ellas. 


\section{Formación de capacidades para el Desarrollo Sostenible}

Anteriormente, se señaló, que en la consecución contextos inteligentes por un desarrollo sostenible era imprescindible, urgente y necesario, asumir la teoría del desarrollo humano como sustento teórico metodológico de dicho modelo. La asunción de dicha teoría no está dada a que rechace la visión anterior centrada en la producción de bienes, servicios o resultados, sino que, al referirse al desarrollo, no se trata del desarrollo de bienes o resultados, sino de resaltar la importancia del talento humano. Significa entonces, que se sustituye por una visión multidimensional, inter y transdisciplinaria centrada en la ampliación de las capacidades de las personas para lograr una gestión sostenible de los bienes, servicios y resultados, de manera que satisfagan las necesidades de las personas para su bienestar y prosperidad (BERTONI et al., 2011; DUBOIS, 2014; COSTAMAGNA; LARREA, 2017).

La formación de capacidades es el proceso en el cual los actores sociales del municipio incrementan sus conocimientos, actitudes y prácticas en los ámbitos técnico-productivos, socio-organizativos, para responder a las contradicciones internas y externas y sostenerse en el tiempo. En la gestión para el desarrollo en el municipio, se valora la combinación de los conocimientos, actitudes y prácticas (CAP) en la organización de acuerdos con los estándares sociales. El desarrollo de los procesos en manos de los propios actores sociales de la comunidad exige un esfuerzo dirigido al fortalecimiento de sus capacidades.

En la medida en que los municipios se transforman, deben formar capacidades diversas. Sin embargo, es importante reconocer que no lo hacen simplemente como un agregado de individuos. Las capacidades no son solamente la suma total de las capacidades individuales. Es un concepto mucho más rico y complejo que entreteje las fuerzas individuales en una trama más fuerte y resistente. Si los municipios quieren formar sus capacidades, deben hacer algo más que expandir las habilidades humanas individuales. Tienen también que crear las oportunidades y estímulos para que las personas utilicen y amplíen dichas habilidades. Así, la formación de las capacidades tiene lugar no sólo en los individuos, sino también entre ellos, entre las instituciones y redes que crean, a través de lo que se ha llamado el patrimonio social, que mantiene unidas a las sociedades y fija los términos de estas relaciones (PNUD, 2010; DUBOIS, 2014).

El objetivo de gestión del desarrollo es aportar a la construcción colectiva un modelo básicamente participativo, lo que indica que debe generar en los actores, o grupo de actores, la capacidad de construcción de su visión real y factible de acuerdo con sus 
capacidades, contexto e identidad cultural, para los diferentes procesos que se desarrollan en el municipio. La formación de capacidades ubica a hombres y mujeres en el centro de la acción de gestión y es de las funciones más importantes de la universidad en el municipio (OJEDA; RAMOS, 2013).

Peña (2013) señala que la configuración cultura del contexto y diversidad social, es síntesis de necesidad y voluntad de estudiar los rasgos y cualidades que caracterizan al municipio en su gestión hacia los procesos de acciones que contribuyen al desarrollo sostenible. Ella constituye la energía que estimula a la investigación desde la observación e indagación de la realidad municipal, se revela la heterogeneidad de la diversidad social, en cuanto a sus gustos, intereses y preferencias por las actividades productivas, educativas, de salud, deportivas, culturales y otras de la vida cotidiana que permiten, desde la creación y recreación, la formación de capacidades para la comprensión y transformación del contexto, en la cual se destacan sus saberes, tradiciones, costumbres, mitos y valores, expresados en la satisfacción por los procesos de desarrollo de la comunidad.

En primer lugar, hay que hacer una distinción importante entre las capacidades técnicas y las capacidades funcionales transversales, para poner de manifiesto cuál es la naturaleza específica de las capacidades relevantes. Las capacidades técnicas hacen referencia a aspectos específicos de determinadas actividades, que, aun cuando sean fundamentales para el funcionamiento de cualquier organización de un sector específico, resultan irrelevantes para las de otro sector. Lo que las diferencia de las transversales es que, sin éstas últimas, por muy formadas que se encuentren, no producirán resultado alguno significativo. En resumen, las capacidades técnicas no serán operativas sin las funcionales transversales, por lo que son dependientes de ellas. Esta diferenciación se encuentra en todas las propuestas, con una u otra denominación. Las capacidades funcionales transversales son aquellas que se encuentran en cualquier organización pública o privada, sea cual sea su nivel de complejidad o el alcance territorial sobre el que actúan. Son éstas las que interesan para nuestro objetivo, ya que son las que marcan las decisiones, que afectan al funcionamiento presente y futuro de un municipio que pretenda ser sostenible.

El proceso de formación de capacidades incluye capacidades individuales y colectivas, que se distinguen en tres niveles: personas, instituciones y sociedad en su conjunto (DUBOIS, 2014; COSTAMAGNA; LARREA, 2017; SOLER, 2017). Este reconocimiento de las capacidades colectivas y la importancia de las interconexiones entre los tres niveles es la novedad más destacada de esta propuesta de formación. Por un lado, es necesaria la 
diferenciación de los tres niveles tanto a efectos conceptuales, como prácticos. En cada uno hay que identificar los actores más significativos y conocer su funcionamiento. Por otro lado, la importancia que se concede a las interacciones entre los niveles y el funcionamiento del conjunto del sistema, obliga a plantearse un análisis dinámico, que rompe el esquematismo de enfoques anteriores. Las relaciones de los actores con el entorno indican cómo los primeros modifican el segundo y, viceversa, cómo el segundo condiciona a los primeros, y se sitúan en el centro del análisis del desarrollo.

La formación de capacidades en la consecución de Municipios Inteligentes para el Desarrollo sostenible es un proceso mediante el cual los individuos, grupos, organizaciones, instituciones, comunidades incrementan su información, conocimientos, habilidades, actitudes, valores, para realizar funciones esenciales, resolver problemas, definir y lograr objetivos, y entender y responder a sus necesidades de desarrollo en el contexto, y de manera sostenible, lo cual posibilita una gestión para el desarrollo eficiente (SEN, 2000; DUBOIS, 2014; COSTAMAGNA; LARREA, 2017; RAMOS; ARTIGAS; BRITO, 2018). Ello implica cambio de paradigmas, cambio personal y organizacional, mejora de la calidad de las prácticas y cambios de comportamientos.

La integración de las unidades de análisis es imprescindible para la consecución de Municipios Inteligentes por un Desarrollo Sostenible. La fragmentación de las mismas limita una visión multidimensional, inter y transdisciplinar y compleja de la construcción del desarrollo sostenible municipal.

\section{Situación actual de las capacidades de los actores de la triple hélice social para el desarrollo sostenible de municipios inteligentes}

La función de gestión se asume como el proceso de mediación entre los actores de la triple hélice social para el desarrollo (Universidad - Gobierno - Comunidad). En este propósito, se necesita de capacidad institucional, incluyendo capacidades duras vinculadas a su infra-estructura, recursos financieros y materiales, y capacidades blandas vinculadas a sus talentos humanos, su capacidad conceptual, metodológica, política, de comunicación, negociación, prospección, planificación, seguimiento y evaluación, que permita desempeñarse adecuadamente en su actividad profesional.

La situación actual de las capacidades de los actores de la triple hélice social para el desarrollo en la consecución de contextos inteligentes evidencia insuficiencias que se manifiestan en la realidad municipal por la contradicción existente entre las capacidades 
que se poseen por los actores y las que deben poseer para construir un Municipio Inteligente por un Desarrollo Sostenible. Por ello, debe evaluarse de forma crítica las capacidades de los actores sociales de la triple hélice social para su desempeño en la conducción y consecución de un municipio inteligente, y su significación como garantía para el desarrollo sostenible, a tono con las nuevas transformaciones que experimenta la sociedad cubana actual y particularmente los municipios de Mayabeque (RAMOS et al., 2020).

La propuesta de la teoría del desarrollo humano se enmarca en dos referentes teóricos. El primero, la aceptación del desarrollo humano como referencia normativa, lo que supone partir de la propuesta teórica del enfoque de las capacidades, que establece la formación de las capacidades de las personas, instituciones y sociedades como el espacio evaluativo relevante para evaluar, frente a la asunción dominante que la sitúa en los recursos que dispone la sociedad en su conjunto. En segundo lugar, la propuesta de la dimensión local como referencia del espacio donde estudiar el desarrollo. La opción por esta dimensión responde a la hipótesis de que es ese el ámbito más adecuado para analizar los procesos de cambio con contenido de desarrollo humano y los resultados en las personas y la sociedad, así como las dinámicas que explican sus dificultades y posibilidades de consolidación (DUBOIS, 2014; DE SOUZA, 2014; COSTAMAGNA; PEREZ, 2015).

Es de significar, que la característica central del desarrollo humano es su propuesta de un espacio evaluativo alternativo que se sitúa en las capacidades de las personas y no en los recursos que dispone el municipio en su conjunto. Es claro que la modificación sustancial del espacio que se considera trascendente para hacer la evaluación económica, social, cultural, ambiental, política e institucional supone un cambio cualitativo frente al concepto de bienestar dominante, que encuentra su referencia en la disponibilidad global de recursos, cuyo indicador central, la renta per cápita, es el mejor exponente de su olvido de la situación real de las personas.

De acuerdo con los razonamientos que se han venido realizando, la gestión del conocimiento es relevante en la construcción del desarrollo sostenible, siempre y cuando se tenga en cuenta que la sostenibilidad implica cultivar las condiciones y relaciones que generan y sostienen la vida, lo que sólo puede emerger de la interacción humana, movilizando la imaginación, creatividad, capacidad y compromiso de los actores en los procesos de gestión para el desarrollo sostenible de los municipios, organizaciones, comunidades o empresas. En todo caso, siempre se debe estudiar multidimensionalmente en lo económico, lo social, lo cultural, ambiental, lo ecológico, lo ético, lo humano. Además, se incluye investigaciones 
inter y transdisciplinarias, por la complejidad y diversidad del desarrollo sostenible que exige una comprensión amplia y múltiple sobre la realidad social (DE SOUZA, 2011; 2014; DUBOIS, 2014; COSTAMAGNA; LARREA, 2017; RAMOS et al., 2020).

Como resultado de lo planteado hasta el momento, en relación a la consecución de municipios inteligentes por un desarrollo sostenible como proceso de construcción social, de carácter multidimensional, complejo, transdisciplinario, contextual, se exige de capacidades por los actores de la tiple hélice social para el desarrollo para comprender y transformar la realidad municipal. Es con este propósito que el Centro de Estudios para la Gestión del Desarrollo de la Universidad Agraria de la Habana realizó una amplia y profunda reflexión y sistematización teórica sobre el desarrollo sostenible de municipios inteligentes, que implicó realizar una extensa revisión bibliográfica y hemerográfica, que privilegió la satisfacción necesidades, identificar las teorías del desarrollo más destacadas e influyentes, tanto en el debate académico como en las tareas propias de la planeación, interpretar las circunstancias históricas en las cuales se construyen las teorizaciones sobre el proceso de desarrollo, lo que conlleva una verdadera revolución cultural, que obliga a realizar modificaciones de hábitos y comportamientos no solo de los actores públicos, sino también de los ciudadanos. Para disfrutar los beneficios ofrecidos por el uso creciente de la actualización de los conocimientos, habilidades, actitudes, de las tecnologías sociales y técnicas capaces de solucionar los problemas, las personas que viven y trabajan en los municipios inteligentes necesitan actualización de capacidades técnicas y funcionales para usarlas en una gestión para el desarrollo que sea participativa e interactiva.

En este sentido, se determinaron los tres procesos más generales en la consecución de municipios inteligentes por un desarrollo sostenible: (i) teorías y enfoques del desarrollo sostenible en municipios y contextos inteligentes; (ii) gestión para el desarrollo de municipios inteligentes por un desarrollo sostenible; (iii) educación para el desarrollo en contextos y municipios inteligentes por un desarrollo sostenible (BERTONI et al., 2011; DE SOUZA, 2011; 2014; DUBOIS, 2014; COSTAMAGNA; LARREA, 2017; RAMOS; BRITO; MARTÍNEZ, 2017).

De esta forma se sistematizaron e identificaron por el Centro de Estudio un grupo de capacidades funcionales por cada uno de los procesos principales que se llevan a cabo en la consecución de Municipios Inteligentes. A continuación, se presentan capacidades que deben poseer y actualizar los actores de la triple hélice social para el desarrollo (RAMOS et al., 2020). 


\section{A - Teorías y enfoques del desarrollo sostenible de municipios inteligentes}

Capacidades para:

- El entendimiento de la teoría y enfoque de desarrollo humano en la construcción de municipios inteligentes por un desarrollo sostenible;

- La aplicación de los fundamentos teóricos y metodológicos para la consecución de municipios Inteligentes;

- Diseño de modelos mentales que puedan ser cambiados, amplificados, reconstruidos y acomodarlos a nuevas situaciones en municipios inteligentes;

- Aprender, desaprender y reaprender desde el contexto de actuación en que se desempeñan en la consecución de municipios inteligentes;

- Trabajar en equipos en la construcción social de conocimientos.

\section{B - Gestión para el desarrollo de municipios inteligentes por un desarrollo sostenible}

Capacidades para:

- La construcción colectiva de un modelo institucional de gestión contextual;

- El enfoque contexto-céntrico para la difusión de estrategias para el desarrollo;

- Investigación acción, generación de conocimiento, cogeneración y pluralismo;

- La construcción colectiva de un contexto inteligente desde la hoja de ruta de gestión contextual;

- La construcción interactiva de estrategias institucionales.

\section{C-Educación para el desarrollo de municipios inteligentes por un desarrollo sostenible}

- La educación y formación de conocimientos, habilidades, valores, actitudes y prácticas en la aplicación de la teoría y enfoque de desarrollo humano en la construcción de contextos inteligentes;

- La educación en la construcción colectiva de un municipio inteligente desde la hoja de ruta de gestión contextual;

- La comunicación como diálogo de saberes en la Educación para el Desarrollo;

- El enfoque pedagógico y la investigación acción: origen de la reflexión sobre la facilitación. 
Es base para este artículo, la investigación realizada por el Centro de Estudios a partir del 2018, sobre las capacidades de los actores de la triple hélice social para el desarrollo sostenible de municipios inteligentes. Se aplicó en un primer instante el instrumento para la autoevaluación de las capacidades que poseen los actores para la construcción de contextos inteligentes. El siguiente instrumento consistió en una entrevista individual en profundidad con el objetivo de percibir en el dialogo las capacidades que se poseen por los actores en la consecución de contextos inteligentes, lo que permitió cruzar datos y hechos con el aplicado para la autoevaluación de los actores.

Se utilizaron durante la investigación otros instrumentos para la evaluación de las capacidades con el objetivo de registrar la manera como los actores construyen su realidad y experiencia; se indago lo que otras personas piensan o sienten con respecto a la consecución de contextos inteligentes por un desarrollo sostenible. En otro momento se realizó la observación participante a partir de una guía que interactúa con análisis de contenidos de los documentos que se poseen para el desarrollo sostenible (Plan de Desarrollo Municipal, Estrategia de Desarrollo Local, Planificación Estratégica del Municipio), además se realizó el análisis de diálogos de actividades donde interactúan actores, observación de actividades donde se interactúa con actores de las hélices gobierno, universidad y comunidad.

En el siguiente momento de la investigación se procedió a la evaluación de las capacidades funcionales sistematizadas por el Centro de Estudios en el desempeño de los actores sociales de la triple hélice social para el desarrollo del municipio. Una reflexión del resumen de la evaluación de las capacidades en los actores sociales participantes de la investigación es que no se percibió un ¿qué?, el ¿por qué? y el ¿cómo?, comprender y transformar el municipio con las capacidades que se poseen por los actores de la triple hélice social para el desarrollo.

Al valorar ciertos resultados de la evaluación de diferentes instrumentos, se logró determinar la contradicción entre lo que enuncian los actores en la aplicación de los instrumentos y la información brindada por el tercer momento de la investigación y el cruzamiento de la misma con el primer momento. Al analizar en los instrumentos aplicados a los actores participantes en el primer momento, éstos percibieran e interpretaran entre un 80 y 90\% que habían formado capacidades para la gestión del desarrollo. Sin embargo, la información del tercer momento de investigación, con el cruce de la información en los instrumentos con el empleo de los métodos anteriormente mencionados, arrojaran que entre $12 \%$ y $22 \%$ de los actores poseían las capacidades adecuadas para comprender 
y transformar el contexto para una sostenible gestión para el desarrollo, existiendo una diferencia entre la evaluación que se hacen los actores sobre las capacidades que poseen y las que realmente tienen para la gestión del desarrollo en la consecución de municipios inteligentes por un desarrollo sostenible.

La visión de la triple hélice social para el desarrollo para una gestión participativa desde el modelo de desarrollo, cuando se tiene en cuenta la percepción de los problemas desde la visión del gobierno, de los especialistas, de la comunidad y de la universidad, aún no tiene una mirada integrada en el $\mathbf{9 2 . 5 \%}$ de los contextos estudiados, lo que implica insuficientes conocimientos, actitudes y prácticas para la comprensión del municipio y su transformación. Sin embargo, lo más preocupante es cuando se refiere por los actores que se poseen estas capacidades en el $86.8 \%$ de los mismos. Los actores no comprenden, piensan, actúan e interiorizan en los procesos de desarrollo que el conocimiento socialmente relevante es generado de forma participativa e interactiva en el contexto de su aplicación e implicaciones y que la interpretación y transformación de la realidad depende del diálogo de saberes, entre el conocimiento científico y otros "conocimientos tácitos con la participación de los actores locales. Una ciencia de la sociedad, que no tiene intermediario porque es interactiva: ciencia con conciencia.

Por esta razón, las acciones de gestión para el desarrollo en la construcción de municipios inteligentes por un desarrollo sostenible han de dar un giro de 180 grados para alcanzar su visión y objetivos ante métodos y prácticas muy arraigadas en todos los actores sociales que interactúan a nivel de municipio. Es importante tener en cuenta que estas posiciones que se adoptan y forman en los actores siguiendo el paradigma clásico para el desarrollo, se realizan con las mejores de las intenciones. De todo esto, se desprende que los actores sociales no perciben e interpretan, que el grado de coherencia interna de las acciones que se proponen no está en correspondencia con el contexto hacia donde se dirigen (DE SOUZA, 2011; 2014; RAMÍREZ; BURBANO, 2014; SAMPER et al., 2017). En ocasiones se piensa que es algo fácil de solucionar, sin embargo, en la interacción en los municipios se percibe la alta complejidad para alcanzar las transformaciones y el cambio, pues a pesar de la voluntad y del conocimiento sobre qué se debe cambiar, aún traiciona los viejos métodos y prácticas arraigadas durante la vida.

Es evidente entonces, ante las insuficientes capacidades para la consecución de municipios inteligentes por un desarrollo sostenible que presentan los actores de la triple hélice social para el desarrollo, la necesidad de un sistema de formación de capacidades 
tomando en consideración la integración de las unidades de análisis, más los procesos para la consecución de municipios inteligentes por un desarrollo sostenible como son la base teórica y metodológica para el desarrollo a construir: la gestión para el desarrollo conectado a la base teórica metodológica, y el tercero de los procesos, la educación para la gestión del desarrollo. Como se aprecia tanto las unidades de análisis, como los procesos teóricos metodológicos, la gestión y la educación para el desarrollo de integrarse adecuadamente, permiten la construcción del desarrollo sostenibles de municipios y contextos inteligentes.

\section{Visión integradora de las unidades de análisis para un sistema de capacidades en la construcción del desarrollo sostenible}

El modelo de municipios inteligentes por un desarrollo sostenible y el sistema de capacidades para el desarrollo sostenible de municipios inteligentes son aportes teóricos dirigidos a la obtención de nuevos conocimientos sobre el objeto de investigación en este caso los municipios. Ambos tienen puntos de coincidencia y de diferenciación por lo que su estudio necesariamente debe realizarse simultáneamente. Entre ambos existen relaciones muy estrechas, dadas porque el modelo siempre tiene carácter sistémico y el sistema de capacidades se hace más comprensible cuando tiene un modelo que lo representa. En la base de la elaboración de ambos se conjugan procedimientos de la modelación y del enfoque sistémico, por lo que es necesario una reflexión teórica previa al estudio de las especificidades de cada uno.

A partir de lo anterior, se plantea que el modelo de desarrollo es una construcción general dirigida a la representación del funcionamiento de un municipio inteligente por un desarrollo sostenible, a partir de una comprensión teórica distinta a las existentes. Por su parte, el sistema de capacidades es un tipo particular de modelo dirigido a la representación de la estructura de las unidades de análisis, como un todo integrado por componentes que mantienen relaciones funcionales de coordinación y subordinación, que exigen de formación de capacidades a partir del enfoque teórico asumido por el modelo municipio inteligente por un desarrollo sostenible.

En ese mismo sentido, se trata de que los actores de la triple hélice social para el desarrollo comprendan qué capacidades deben poseer, como núcleo de su forma de actuar de manera que se asegure el funcionamiento de sus objetivos más estratégicos. Por eso, más que pensar en una lista de capacidades entendidas cada una de manera independiente, la cuestión es entenderlas como un conjunto interconectado donde todas son necesarias 
e interactúan, retroalimentándose e influyéndose entre sí. Expresado de otra manera, pudiera decirse que se busca una visión integral de todas esas capacidades de manera que se vislumbre la capacidad colectiva, como la habilidad colectiva, o la aptitud de un municipio, organización, sector inteligente para llevar a cabo una función particular, o un proceso, dentro o fuera del sistema. Esa capacidad colectiva integral se compone de una serie de capacidades colectivas que son las que le permiten a una organización hacer cosas y mantenerse (DE SOUZA, 2014; DUBOIS, 2014; KALSEN; LARREA, 2014; COSTAMAGNA; PÉREZ, 2015; COSTAMAGNA; LARREA, 2017).

La principal dificultad de la elaboración de un marco analítico del desarrollo desde el enfoque de las capacidades de municipios y contextos inteligentes de Mayabeque, se encuentra, precisamente, en la complejidad de los contenidos que pretende abarcar. El cambio es la base del desarrollo; sin procesos de cambio que transformen a municipios y contextos no puede hablarse de desarrollo. Pero el análisis de los procesos de cambio, es especialmente complejo (DUBOIS, 2014; MALDONADO, 2016; SOLER, 2017).

En primer lugar, porque, aunque se reconoce que ese es el espacio relevante, se carece de teorías por los actores que ofrezcan las herramientas idóneas para analizar el funcionamiento como sistema de la triple hélice social para el desarrollo, y al mismo tiempo, existe una variedad de enfoques parciales que dificultan consensuar el diseño de políticas, donde inciden la fragmentación, sectorización, que disminuye la relevancia del lado blando de la realidad, que incluye los procesos, relaciones, conexiones, interacciones, interdependencias, contradicciones, implicaciones, cadenas de impacto, etc., que caracterizan y aportan significado a la dinámica compleja y cambiante de la vida en sociedad, en la construcción del desarrollo sostenible de municipios y contextos inteligentes.

En segundo lugar, el desarrollo se entiende cada vez más como un proceso incierto, especialmente a partir de la revisión de los postulados dominantes que ha supuesto el abandono de la modernización como modelo a alcanzar. Ya no hay una única referencia sobre cuál debe ser el resultado a aspirar. Ahora el desarrollo se convierte en una aventura que cada sociedad debe emprender sin tener establecidos los caminos por los que deba transitar. No hay un camino al desarrollo y no se tienen referentes generalizables que permitan diseñar previamente la senda. Al no tener pautas del final ni de la secuencia a seguir, el proceso de cambio se convierte en objeto de especial atención. 
De ahí que la pregunta ¿cómo ocurre el cambio?, se haga obligada, si se quieren conseguir los objetivos propuestos. Se considera cuatro elementos, contexto, instituciones, actores y acontecimientos, que se combinan e interactúan entre sí, creando un camino complejo que incluye diferentes tiempos de actividad, más o menos intensa, y combinaciones diferentes de esos cuatro elementos. Los procesos de cambio resultan, pues, muy complejos e impredecibles, y ni siquiera el poder señalar en qué tipo de dinámica se encuadran, resuelve la incertidumbre. Cabe agregar que, las insuficientes capacidades de los actores en la construcción de la senda hacia el desarrollo sostenible, exigen de un sistema de capacidades colectivas para los actores de la triple hélice social para el desarrollo en municipios y contextos inteligentes (DE SOUZA, 2011; COSTAMAGNA; PEREZ, 2015; MALDONADO, 2016; SOLER, 2017, RAMOS et al., 2020).

En tercer lugar, una cosa es señalar las deficiencias de determinados enfoques y otra muy diferente es proponer cuáles pueden reemplazarlos ventajosamente. En cualquier caso, es importante resaltar que el problema no se encuentra en que los problemas no puedan tratarse o en que no se han aplicado correctamente las herramientas, sino que las que se utilizan han perdido vigencia, se encuentran desactualizadas y no funcionan porque se basan en supuestos inapropiados para los problemas complejos, y por eso cuando se aplican en contextos equivocados pueden producirse efectos colaterales negativos. En este caso, la propuesta a partir de los estudios e investigaciones del Centro de Estudios, es la integración de las unidades de análisis tratadas en el documento y la propuesta de solución en un sistema de capacidades como imprescindible y necesario en la construcción del desarrollo sostenible de municipios y contextos inteligentes.

Tomase como referencia al municipio (contextos, instituciones, organizaciones, empresas, comunidades) para un primer análisis. Es evidente entonces que, la consecución de municipios inteligentes y el desarrollo forman una unidad imprescindible para el desarrollo sostenible en Mayabeque, pues para alcanzar la inteligencia municipal y el desarrollo sostenible, se precisa de atributos del nuevo modo de generación de conocimiento como son, conocimiento generado en el contexto de su aplicación e implicaciones, relación transdisciplinaria, diversidad de actores y organizaciones, reflexividad y compromiso sociales, además de control social, lo que exige de un sistema de capacidades para la formación de los actores de la triple hélice social para el desarrollo, desde la praxiología de la gestión de la innovación institucional, que corresponde a la práctica de la gestión de cambios en las reglas del juego de un municipio inteligente por un desarrollo sostenible (DE SOUZA, 2011; 2014; DUBOIS, 2014; KARLSEN; LARREA, 2014; COSTAMGANA; LARREA, 2017). 
Si en un municipio inteligente por un desarrollo local se cuestiona las dimensiones ético-filosófica, social, política, conceptual y metodológica de su modelo de actuación centrado en la oferta, y lo reemplaza por otro centrado en el contexto, este es un cambio del tipo transformacional, donde ideas cualitativamente diferentes fueron generadas, procesadas, reconfiguradas e incorporadas desde los procesos de ciencia e innovación, formación y extensión. Eso significa que, para un municipio inteligente en la construcción del desarrollo sostenible, cambio e innovación tienen un significado semejante, porque todo cambio transformacional genera innovación y toda innovación es derivada de un cambio transformacional. Como desde esta perspectiva, ambos (innovación y cambio) son un producto de la interacción social, se utilizará de forma intercambiable los términos "cambio" e "innovación" (DE SOUZA, 2014; RAMOS et al., 2020).

En efecto, tradicionalmente la capacidad institucional de gestión ha sido analizada en función de las capacidades individuales. En este sentido, existe una gran heterogeneidad entre los municipios que construyen el desarrollo. Es posible coincidir en que en el área de gestión del desarrollo se cuenta con talentos de experiencia; no obstante, en este cambio de época no todas las experiencias previas continuarán siendo pertinentes, y se requiere la construcción de un sistema de capacidades institucionales para la gestión de la innovación, que contribuyan a alcanzar la sostenibilidad institucional de los municipios y contextos inteligentes.

La capacidad institucional es un concepto multidimensional. La cooperación internacional conceptualizó capacidad institucional de forma asociada a apenas dos aspectos, construcción de infraestructura y formación profesional, lo que era congruente con la política general de reconstrucción. Por ejemplo, para las organizaciones de ciencia y tecnología agropecuaria eso significó la construcción de edificios sedes, estaciones experimentales, laboratorios y formación de sus investigadores, principalmente en diferentes disciplinas de las ciencias agrarias. Mientras estos aspectos son todavía críticas para muchas organizaciones de países en desarrollo, en un cambio de época otros asumen una importancia absolutamente insospechada para todos los municipios en la construcción del desarrollo sostenible.

Uno de estos aspectos críticos es el esfuerzo del Centro de Estudios para la Gestión del Desarrollo (CEGED), en la construcción de marcos conceptuales, metodológicos y culturales autóctonos. Esta capacidad institucional es absolutamente imprescindible para (re)construir las bases de la sostenibilidad institucional de los municipios, en el contexto de la vulnerabilidad generalizada creada por las turbulencias, inestabilidad, discontinuidad, 
desorientación, incertidumbre e inseguridad, derivadas de los cambios estructurales y simultáneos en las relaciones de producción, poder, experiencia humana y cultura. Mientras los cambios globales que están cambiando la época son los mismos para todos, sus significados e impactos no lo son. No hay dos municipios iguales, lo que implica interpretaciones e implicaciones diferentes (DE SOUZA, 2014; COSTAMAGNA; LARREA, 2017; RAMOS et al., 2020).

En este contexto, el CEGED conceptualiza la capacidad institucional para la gestión del desarrollo como la capacidad organizacional para ejecutar y aplicar marcos autóctonos de referencia que permitan al municipio, contextualizar, interpretar, aprender, reconfigurar, generar, innovar, juzgar y cambiar. Tener recursos financieros y no tener esta capacidad puede condenar a una organización a la imitación y a la improvisación generalizadas, lo que puede ser fatal para su sostenibilidad institucional. Construir este tipo de capacidad implica practicar el desarrollo de, no el desarrollo en las organizaciones.

Es de significar, que un sistema de capacidades en la construcción de municipios inteligentes por un desarrollo sostenible, con visión integradora de las unidades de análisis, es imprescindible para contrarrestar la improvisación y la imitación en los procesos de cambio que está prevaleciendo en la actualidad en los municipios de Mayabeque, lo que no favorece a la innovación institucional. Las decisiones y las acciones se están transformando en el producto de una improvisación sin compromiso con sus consecuencias. La improvisación será siempre necesaria y saludable, siempre y cuando resulte de la presión para ser flexible y creativo, frente a situaciones no previstas. Sin embargo, no es aceptable que la improvisación pase a ser la regla en el marco de la cual se maneja situaciones que podrían haber sido proyectadas o imaginadas con antelación.

En efecto, en un cambio de época, la improvisación puede ser fatal. En una época de cambios, la mayoría de los elementos de referencia para la implementación de una actividad están claros y disponibles, mientras en un cambio de época es muy difícil distinguir lo que es de lo que no es pertinente. Al contrario, en un cambio de época, la capacidad para ejecutar estrategias de negociación, sensibilización, formación, facilitación, investigación, gestión, institucionalización, etc., es una de las capacidades más demandadas en la formación de los actores sociales participantes.

De acuerdo con la propuesta del CEGED, un modelo municipio inteligente por un desarrollo sostenible es un marco que articula elementos de referencia para orientar e influenciar la forma de pensar, decidir y actuar del equipo de gestión de la triple hélice 
social para el desarrollo de una organización. La construcción y la institucionalización de un modelo de desarrollo facilitan el desarrollo de procesos de innovación institucional, que contribuyen a construir la sostenibilidad institucional.

Un modelo institucional de municipio inteligente por un desarrollo sostenible no depende de los atributos ni de las capacidades de la gerencia, sino que define los elementos de referencia que deben influenciar la forma de pensar, decidir y actuar de cualquier gestor en la organización que establece dicho modelo. Por tanto, un equipo de gestión no se forma de la noche a la mañana, sino más bien emerge del proceso de construcción del modelo institucional de desarrollo sostenible de municipios inteligentes: construcción, validación, implementación e institucionalización (DE SOUZA, 2014; KARLSEN; LARREA, 2014; COSTAMAGNA; PÉREZ, 2015; COSTAMAGNA; LARREA, 2017).

Un sistema de formación de capacidades en el proceso de construcción colectiva de un modelo institucional municipio inteligente por un desarrollo sostenible, es un momento privilegiado para la organización, por su efecto educativo y capacitador, sobre todo de los actores que participan del proceso. Por eso, los líderes y los facilitadores del proceso deben socializar muy bien sobre este momento. Las discusiones, las reflexiones, los debates, las negociaciones y los acuerdos son parte de la socialización necesaria para el cambio de comportamiento de los gerentes.

Es de significar, que la metodología para estructurar estos momentos debe incluir una preocupación por la posibilidad de poseer las capacidades imprescindibles para una amplia participación en discusiones tan profundas y largas como sean necesarias y posibles dentro del tiempo disponible. Los resultados intangibles logrados en este proceso son tan importantes como el documento generado. Las propuestas escritas en el documento primero deben ser incorporadas en los modelos mentales de los participantes. Pasado este momento, resta ejecutar e implementar una estrategia para validar e institucionalizar el nuevo modelo de desarrollo municipio inteligente por un desarrollo sostenible (DE SOUZA, 2014; RAMOS et al., 2020).

La aproximación a la complejidad en la concepción del Modelo Municipio Inteligente que más ha incidido es la Investigación Acción para el Desarrollo Municipal (IADM), planteada por Karlsen y Larrea (2014), qué definen el concepto de complejidad municipal como un contexto en el que existe una serie de actores autónomos, pero interdependientes en un territorio. Dichos actores pueden tener perspectivas distintas de cuáles son los principales problemas que tiene el territorio y también sobre cuáles son las posibles soluciones. El último 
elemento de la complejidad es que ninguno de los actores cuenta con poder suficiente para solucionar los problemas que considera críticos mediante el ordeno y mando. Esto significa que, cuando hay una situación de complejidad municipal, no funciona el ordeno y mando y es necesario realizar otro tipo de mecanismos (KARLSEN, LARREA, 2014).

Es precisamente a este proceso de construcción de nuevos mecanismos a lo que contribuye la IADM. En esta aproximación a la complejidad municipal se ha de manifestar de manera integrada como se indicaba anteriormente, que conlleva a la formación de capacidades técnicas y funcionales, que visualiza el desarrollo no de los procesos sino de las personas en la consecución de municipios inteligentes por un desarrollo sostenible, lo que conlleva al diseño de un sistema de capacidades para el desarrollo sostenible de municipios inteligentes por un desarrollo sostenible (KALSEN; LARREA, 2014; COSTAMAGNA; LARREA, 2017; RAMOS et al., 2020).

El diseño de un sistema de capacidades para el desarrollo sostenible de municipios y contextos inteligentes de Mayabeque, sigue las siguientes premisas, basadas en la creencia de los actores de la triple hélice social para el desarrollo, en el proceso de construcción del modelo, con la participación de una diversidad de actores del gobierno, universidad, comunidad, de que:

- Su desempeño responde a su condición de sistema complejo, abierto, dinámico, multidimensional y no-lineal, sujeto a límites y contradicciones;

- El contexto, en sus dimensiones ambiental, económica, social, política, cultural, institucional, tecnológica y ética, es la referencia superior para orientar sus marcos para pensar, decidir y actuar, donde la inestabilidad e incertidumbre son las premisas para la planificación y gestión;

- Los criterios que influencian sus decisiones y acciones deben ser negociados en sintonía con las premisas de su visión de contexto;

- Sólo los que aprenden haciendo son capaces de transformar lo que hacen, lo que establece la "cultura del aprender haciendo";

- No existe una, sino múltiples causas para cada efecto observado, que a su vez interactúa con estas causas, generando un proceso de mutuas influencias;

- Su modo de acción resulta de su sensibilidad teórica y metodológica para interactuar con los actores del contexto;

- Los sectores, son sistemas complejos, abiertos y dinámicos con múltiples funciones;

- La práctica científica es sinónimo de "comprender para transformar"; 
- Las organizaciones de desarrollo son sistemas complejos, abiertos y dinámicos con múltiples funciones, donde la principal es funcionar como facilitador del cambio y desarrollo en su entorno relevante;

- Los seres humanos que integran las organizaciones son ciudadanos, talentos humanos con imaginación y capacidad para crear más allá de su conocimiento y experiencias previas.

Lo expuesto con anterioridad es demasiado simplificado para generar comprensión. El propósito de presentarlo así es solamente el de estimular su discusión y transformación, por los actores sociales de la triple hélice que deseen explorar sus implicaciones para sus respectivas organizaciones, proyectos, comunidades, sectores, municipios. Lo más importante en este esfuerzo será la imaginación, capacidad y compromiso de los que decidan aportar a la construcción del desarrollo sostenible (DE SOUZA, 2014; KARLSEN; LARREA, 2014; DUBOIS, 2014; COSTAMAGNA; PEREZ, 2015; COSTAMAGNA; LARREA, 2017; MALDONADO, 2016; SOLER, 2017).

En principio, el sistema de capacidades en la formación del talento humano de Mayabeque debe incluir un esfuerzo para pensar la complejidad, de forma sistémica, bajo las reglas metodológicas de la dialéctica, creativamente y éticamente. En este propósito, pensar la complejidad implica pensar de forma sistémica como un mundo de interacciones, conexiones, relaciones, cadenas de impacto, si se trata de construir desarrollo sostenible de municipios y contextos inteligentes. Por lo que, las reglas del pensamiento sistémico aplicado a los sistemas sociotécnicos se han de manifestar en la consecución de municipios inteligentes por un desarrollo sostenible de la siguiente manera: pensando contextualmente, diferencialmente, epistémicamente, intencionalmente, no-linealmente, procesualmente, relacionalmente, dialécticamente e integralmente.

Un sistema de capacidades para el desarrollo sostenible de municipios inteligentes de Mayabeque, en la formación de los actores de la triple hélice social para el desarrollo, requiere combinar el pensamiento duro con el pensamiento blando, con el último prevaleciendo sobre el primero. La prevalencia del pensamiento duro de la época del industrialismo ha creado la actual vulnerabilidad de los municipios de Mayabeque, por elevar de forma exclusiva la importancia de las cosas, hechos y fenómenos visibles, concretos, cuantificables y valorados económicamente. Eso disminuyó la relevancia del lado blando de la realidad municipal y de su construcción del desarrollo municipal, que incluye los procesos, relaciones, conexiones, interacciones, que caracterizan y aportan significado a la dinámica compleja y cambiante de la vida, lo que hace evidente entonces, las insuficiencias de capacidades para tal fin en los actores de la triple hélice social para el desarrollo. 
Es de significar que la prevalencia del pensamiento blando sobre el pensamiento duro en el futuro de los municipios de Mayabeque no será posible si los sistemas de educación no lo institucionalizan, bajo un compromiso con la regla del desarrollo, lo que sigue apuntando a un sistema de capacidades que potencie el pensamiento blando en contextos inteligentes que vislumbran en el futuro el desarrollo sostenible.

\section{Consideraciones finales}

El desarrollo del municipio en su contribución al desarrollo sostenible exige de un sistema de capacidades para el desarrollo de municipios inteligentes, pasando primero por un esfuerzo colectivo para aprender a desaprender las reglas de la vulnerabilidad, antes de aprender a aprender las reglas de la sostenibilidad, las cuales conllevan un aprendizaje crítico y creativo más constructivo que el aprendizaje imitativo. Al incluir personas en su proceso, el desarrollo incluye valores, creencias, intereses, principios, hipótesis, premisas, teorías, aspiraciones, compromisos, contradicciones y, por lo tanto, no ocurre de forma idéntica en contextos diferentes.

Un sistema de formación de capacidades de los actores de la triple hélice social para el desarrollo, que toma en consideración la integración de las unidades de análisis, más los procesos para la consecución de municipios inteligentes por un desarrollo sostenible, permiten la construcción del desarrollo en municipios y contextos inteligentes si logra combinar el pensamiento duro con el pensamiento blando de la realidad municipal.

\section{Referências}

BERTONI, R.; CASTELNOVO, C.; CUELLO, A.; FLEITAS, S.; PERA, S.; RODRÍGUEZ, J.; RUMEAU D. ¿Qué es el desarrollo? ¿Cómo se produce? ¿Qué se puede hacer para promoverlo? Construcción y análisis de problemas del desarrollo. Montevideo: Universidad de la República, 2011.

BOUSKELA, M.; CASSEB, M.; BASSI, S.; DE LUCA, C.; FACCHINA, M. La ruta hacia las smart cities: migrando de una gestión tradicional a la ciudad inteligente. Washington, DC: Banco Interamericano de Desarrollo, 2016.

BÜTTENBENDER, P. L.; SAUSEN, J. O. Practicas innovadoras de gestión del desarrollo en la región de frontera: propondo constructo de gobernanza innovadora y desarrollo territorial. Revista Brasileira de Gestão e Desenvolvimento Regional, v. 16, n. 2, p. 459-471, 2020.

CASTILLO, L.; LAVÍN, J.; PEDRAZA, N. A. La gestión de la triple hélice: fortaleciendo las relaciones entre la universidad, empresa, gobierno. Multiciencias, v. 14, n. 4, p. 438-446, oct./dic. 2014.

CELAYA, M.; BARAJAS, M. La Academia y el sector productivo en Baja California. Los actores y su capacidad de vinculación para la producción, difusión y transferencia del conocimiento y la innovación. Revista Región y Sociedad, v. 24, v. 55, p. 41-80, 2012. 
CHANG, H. El Modelo de la Triple Hélice como un medio para la vinculación entre la Universidad y la Empresa. Revista Nacional de Administración, v. 1, n. 1, p. 85-94, 2010.

CORRALES, M. El modelo de la triple hélice en la comprensión y desarrollo de proyectos sociales complejos en Costa Rica. Revista Nacional de Administración, v. 5, n. 1, p. 115-130, 2014.

COSTAMAGNA, P; PÉREZ, S. Enfoque, estrategias e información para el desarrollo territorial. Los aprendizajes desde ConectaDEL. Buenos Aires: Conectadel, 2015.

COSTAMAGNA, P.; LARREA, M. Actores facilitadores del desarrollo territorial: una aproximación desde la construcción social. Madrid: Orkestra - Instituto Vasco de Competitividad, 2017.

CUBA. Constitución de la República de Cuba. La Habana. Habana: Política, 2019.

DE SOUZA, J. La geopolítica del conocimiento y la gestión de procesos de innovación en la época histórica emergente. Campina Grande: Red Nuevo Paradigma para la innovación institucional en América Latina, 2011.

DE SOUZA, J. La crisis global de la innovación para el desarrollo. Del positivismo al constructivismo para construir modos de vida localmente sostenibles. Revista Cubana de Ciencias Agrícolas, v. 48 n. 1, p. 11-15, 2014.

DÍAZ-CANEL, M. Universidad 2012. Conferencia magistral durante el 8. Congreso Internacional de Educación Superior, Habana, 2012.

DUBOIS, A. Marco teórico y metodológico del Desarrollo Humano Local. Bilbao: Instituto sobre Estudios de Desarrollo y Cooperación Internacional. Editorial Universidad País Vasco, 2014.

GAETE, R. A. El concepto de responsabilidad social universitaria desde la perspectiva de la alta dirección. Cuadernos de Administración, v. 31, n. 53, p. 97-107, 2015.

GONZÁLEZ, D. T. El Modelo de Triple Hélice de relaciones universidad, industria y gobierno: Un análisis crítico. ARBOR Ciencia, Pensamiento y Cultura. v. CLXXXV, n. 738, p. 737-755, 2009.

GRADILLAS, M. Propuesta para la formulación de una estrategia de gestión de conocimiento. 2002. Disponível em: http://www.gestiondelconocimiento.com. Acesso em: 2 jun. 2010.

KARLSEN, J.; LARREA, M. Desarrollo territorial e investigación acción Innovación a través del diálogo. Madrid: Orkestra - Instituto Vasco de Competitividad, 2014.

LEYDESDORFF, L. The Knowledge-Based Economy and the Triple Helix Model. Annual Review of Information Science and Technology, v. 44, p. 367-417, 2010.

LEYDESDORFF, L. Triple Helix of university-industry-government relations. New York: Springer, 2013.

LÓPEZ, S.; MEJIA, J.; SCHMAL, R. Un acercamiento al concepto de la transferencia de tecnología en las universidades y sus diferentes manifestaciones. Panorama Socioeconómico, v. 24, n. 32, p. 70-81, 2006.

LÓPEZ, J. Modelos interpretativos de la relación estado-empresa-universidad. Revista Clío América, v. 8, n. 15, p. 111-122, 2014.

LUEG, C. Presentación. Gestión del conocimiento y tecnologías de la información: relaciones y perspectivas. Novática, n. 155, p. 4-7, ene./feb. 2002.

LUENGO, M.; OBESO, M. El efecto de la triple hélice en los resultados de innovación. Revista de Administración de Empresas, v. 53, n. 4, p. 388-399, 2013.

MALDONADO, C. E. Transformación de la no-Complejidad a la Complejidad. Ingeniería, v. 3, n. 21, p. 411-426, 2016. 
MATILLA, A. Municipio y administración local: breves glosas al hilo del contexto jurídico cubano actual. En: PÉREZ, L.; DÍAZ, O. ¿Qué municipio queremos? Respuestas de Cuba en clave de descentralización y desarrollo local. La Habana: Editorial UH, 2019. p. 175-192.

MUJICA DE LÓPEZ, M.; MARÍN, F.; SMITH, H.; LOVERA, M. I. Municipio innovador, un modelo para el desarrollo local sostenible. Multiciencias, v. 8, p. 130-136, dic. 2009.

OJEDA, R.; RAMOS, A. E. Municipio inteligente por un desarrollo agrario y rural sostenible. Mayabeque: Biblioteca Virtual para el Desarrollo del Ceged - Unah, 2013.

ORGANIZACIÓN DE LAS NACIONES UNIDAS PARA LA EDUCACIÓN, LA CULTURA Y LA CIENCIA (UNESCO). La nueva dinámica de la Educación Superior y la búsqueda del cambio social y el desarrollo. Conferencia Mundial de Educación Superior - Comunicado Final, Paris, 2009.

PEÑA, M. A. Gestión de la recreación física para el desarrollo humano local desde comunidades rurales de Omaja. Tesis (Doctorado en Ciencias de la Cultura Fisca) - Universidad de las Ciencias de Cultura Física, La Habana, 2013.

PINEDA, K.; MORALES, M.; ORTIZ, M. Modelos y mecanismos de interacción universidad-empresa-Estado: retos para las universidades colombianas. Equidad y Desarrollo, v. 19, n. 15, p. 41-67, 2012.

PROGRAMA DE NACIONES UNIDAS PARA EL DESARROLLO (PNUD). Informe sobre Desarrollo Humano. Nueva York, 2010. Disponível em: http://hdr.undp.org/es/informes/mundial/idh2010/. Acesso em: jun. 2015.

RAMOS, A. E.; ARTIGAS, E.;BÁEZ, D. La responsabilidad social de la universidad y su integración en la consecución de municipios inteligente por un desarrollo próspero y sostenible. In: PÉREZ, S., BUENO, E.; AGUILAR, F. Economía, desarrollo y territorio. Los desafíos y propuestas para el segundo milenio. Ciudad de Mexico: Red de Estudios Municipales, 2015. p. 416- 436.

RAMOS, A. E.; BRITO, A.; MARTÍNEZ, R. La universidad en la consecución de municipios inteligentes por un desarrollo local sostenible. DELOS Desarrollo Local Sostenible, v. 10, n. 30, 2017.

RAMOS, A. E.; BRITO, A.; ARTIGAS, E.; MARTÍNEZ, R. De un municipio tradicional a un municipio inteligente por un desarrollo local sostenible. DELOS Desarrollo Local Sostenible, v. 12, n. 36, 2020.

RAMOS, A. E.; BRITO, A.; ARTIGAS, E.; MARTíNEZ, R. La triple hélice social para el desarrollo desde la gestión del conocimiento. DELOS Desarrollo Local Sostenible, v. 11, n. 33, 2018.

RAMÍREZ, G. P.; BURBANO, L. C. La planeación estratégica: una herramienta de gobierno en el diseño y gestión de políticas públicas. Colombia: Gobierno Bogotá, 2014.

SAMPER, M.; ARZE, J. C.; AVENDAÑO, P.; MORENO, M. Tareas operativas en la gestión social del desarrollo de los territorios rurales. San José, Costa Rica: Instituto Interamericano de Cooperación para la Agricultura, 2017.

SEN, A. A decade of human development. Journal of Human Development, v. 1, n. 1, p. 17-23, 2000.

SOLER, Y. Teorías sobre los sistemas complejos. Administración y Desarrollo, v. 47, n. 2, p. 52-69, 2017.

VALLAEYS, F. La responsabilidad social universitaria: un nuevo modelo universitario contra la mercantilización. Revista Iberoamericana de Educación Superior, v. 5, n. 12, p. 105-117, ene. 2014. 